\title{
Bur open Lay perspectives of successful ageing: a systematic review and meta-ethnography
}

\author{
Theodore D Cosco, ${ }^{1}$ A Matthew Prina, ${ }^{1}$ Jaime Perales, ${ }^{2}$ Blossom C M Stephan, ${ }^{3}$ \\ Carol Brayne ${ }^{1}$
}

To cite: Cosco TD, Prina AM, Perales J, et al. Lay perspectives of successful ageing: a systematic review and meta-ethnography. BMJ Open 2013;3:e002710. doi:10.1136/bmjopen-2013002710

- Prepublication history for this paper is available online. To view these files please visit the journal online (http://dx.doi.org/10.1136/ bmjopen-2013-002710).

Received 11 February 2013 Revised 30 April 2013 Accepted 30 April 2013

This final article is available for use under the terms of the Creative Commons Attribution Non-Commercial 2.0 Licence; see http://bmjopen.bmj.com

${ }^{1}$ Department of Public Health and Primary Care, Cambridge Institute of Public Health, University of Cambridge, Cambridge, UK

${ }^{2}$ Parc Sanitari Sant Joan de Deu, Universitat de Barcelona, Barcelona, Spain ${ }^{3}$ Institute of Health and Society, Newcastle University, Newcastle, UK

\section{Correspondence to} Theodore D Cosco; tdc33@cam.ac.uk

\section{ABSTRACT}

Objectives: The aim of the current study was to conduct a systematic review of lay perspectives of successful ageing (SA), synthesise these data using a metaethnographic framework and to provide a snapshot of extant lay perspectives of SA.

Design: A systematic review of layperson perspectives of SA was conducted across MEDLINE, PsycInfo,

CINAHL, EMBASE and ISI Web of Knowledge.

Participants: Peer-reviewed studies conducting qualitative investigations of lay perspectives of SA were included. Included studies were coded and analysed using NVivo V.9 to examine underlying themes of SA.

Results: The search strategy identified 7285 articles; 26 articles met the inclusion criteria. Laypersons identified psychosocial components, notably engagement (eg, social engagement), and personal resources (eg, attitude) as integral components of SA more often than 'physiological' components, such as longevity or physical functioning. These results also highlight the profound under-representation of nonWestern countries and the cultural homogeneity of research participants.

Conclusions: The current study reveals the importance laypersons place on incorporating psychosocial components into multidimensional models of $S A$, as well as highlighting the need for increased research with under-represented populations.

\section{INTRODUCTION}

Despite an increasing focus on the improvement of the quality of life throughout the life course, there is no generally accepted definition of what it means to age well. What 'successful ageing (SA)' is, or is not, is a contentious issue. Since the inception of the term, subjective interpretations of SA have generated an increase in disparate perspectives and conceptualisations. Depending on the context, objectives and sample characteristics of a study, the definition of SA has varied significantly. ${ }^{1}$ In the absence of a consensus definition, the generalisability of SA studies has been severely impeded, inhibiting cross-study comparisons.

\section{ARTICLE SUMMARY}

Article focus

- Currently, there is no consensus definition of successful ageing (SA).

- The current study provides a comprehensive snapshot of qualitative studies of layperson perspectives of SA.

Key messages

- SA is much more complex than simply physical health.

- Psychosocial (eg, attitude) factors were the most frequently mentioned components of SA.

- Layperson perspectives advocate the inclusion of components of SA that go beyond physical health.

Strengths and limitations of this study

- This article conducts a systematic review of qualitative studies.

- Meta-ethnography involves the subjective interpretation of secondary data, which is itself a subjective interpretation.

- Languages that did not have 'successful ageing' in their vernacular used approximations of the term.

The most popular model of SA, Rowe and Kahn's ${ }^{23}$ conceptualisation of $\mathrm{SA}$, is primarily biomedical. This and other biomedical models of SA focus on the physiological or cognitive aspects of health, as captured by metrics such as the Mini Mental State Examination $^{4}$ or the Activities of Daily Living scale. ${ }^{5}$ Rowe and Kahn's ${ }^{2}{ }^{3}$ model suggests that high cognitive/physical functioning, low risk of illness and active engagement comprise SA. This widely used model provides the theoretical underpinnings for many operational definitions of SA. ${ }^{1}$ Although these researcher-driven conceptualisations of SA are popular, they have, however, been subject to criticism due to their biomedical focus, without explicit input of layperson perspectives. $^{6}$

The aim of the study was to provide a comprehensive review of studies examining lay 
perspectives of SA, in order to augment the many researcher-driven conceptualisations of SA with insights from qualitative research. The most recent reviews of operational definitions of $\mathrm{SA}^{1}$ and qualitative perspectives of $\mathrm{SA}^{7}$ reveal that there are more than twice as many studies positing operational definitions of SA as there are studies examining lay perspectives of SA. However, a study examining several different SA models, that is, biomedical, psychosocial and lay models, found the multidimensional lay model to be the strongest. ${ }^{8}$ Through qualitative studies, laypersons are given a platform to voice their opinions and perspectives on research topics. ${ }^{9}$ Therefore, the incorporation of layperson perspectives expands and complements researcherdriven conceptualisations of SA, with the potential to improve both the quality and impact of research, ${ }^{10}$ increasing the validity and practical relevance of SA models. ${ }^{11}$ This review expands upon a previous review of lay perspectives by Hung et $a l^{7}$ through a broadened search strategy, an augmented temporal search span and the inclusion of non-English articles. Further, while Hung $e t a l^{7}$ focused on the umbrella concept of 'healthy ageing', which they describe as capturing, 'active ageing', 'positive ageing', 'robust ageing', 'ageing well' as well as SA, the current review focuses specifically on SA.

\section{METHODS}

\section{Search strategy}

A systematic review of the literature in PubMed, PsycInfo, ISI Web of Knowledge, EMBASE and the CINAHL databases was initially conducted between 31 May and 7 June 2011 and then updated on 23 March 2013; all literature published before 23 March 2013 was eligible for inclusion. The specific search strategy includes "successful ageing" along with seven SA synonyms: robust ageing, optimal ageing, positive ageing, healthy ageing, productive ageing, effective ageing and ageing well. These phrases were used with both "aging" and "ageing" spelling conventions, put in quotations, and linked via the Boolean operator "OR". Where possible, the wildcat operator "*” was inserted to capture all permutations of the phrase. Furthermore, where possible, in a given database, non-human studies were excluded. For example, the search input for the phrase "successful ageing" in PubMed was "successful* aging" OR "successful* ageing", which was searched as "successful* aging" [All Fields] OR "successful* ageing" [All Fields] AND "humans" [MeSH Terms].

This process was repeated across the six databases using the seven SA-related phrases. The SA-related terms were included to capture studies that, for example, listed 'ageing well' in their keywords but asked "What is your definition of successful ageing?" in interviews with participants. If only 'successful ageing' had been used in the search strategy, it would have been missed. Therefore, in an effort to capture every SA instance, the seven SA-related terms were used in the search strategy.
Relevant articles referenced in the captured studies were also included.

\section{Study inclusion}

Peer-reviewed research articles conducting qualitative research with laypersons on the components of SA were included. Studies were considered to be qualitative if participants were asked open-ended or semiopen-ended question(s). Studies discussing synonyms of SA without specific reference to SA, or components of SA, were excluded. Non-peer reviewed articles such as dissertations, opinion pieces and letters to the editor, as well as review articles, were excluded.

As the intent was to provide a comprehensive review of lay perspectives of SA, studies were neither excluded nor weighted based on study characteristics or methodological rigour, as there is no established methodology for quality assessment of construct reviews. ${ }^{12}$

\section{Data extraction}

A title and abstract review was conducted (TDC, AMP and JP) to identify relevant articles for full-text extraction. Disagreements regarding inclusion were resolved by discussion. No language restrictions were made; non-English articles were translated by multilingual staff at the Cambridge Institute of Public Health, Cambridge University. Information regarding the definitions and components of SA were extracted from authors' descriptions and syntheses of participants' responses as well as direct quotes from study participants. Where possible, the percentage of respondents referencing each SA component in a given study was noted. In studies where participants ranked the relative importance of each SA component, these data were recorded.

\section{Synthesis}

Themes created by study authors and direct quotes from study participants were identified, coded and analysed in NVIVO V.9. The different components of SA were analysed using a metaethnographic framework. Meta-ethnography is a method with which to synthesise qualitative studies through an inductive analysis and integration of interstudy themes. ${ }^{13}$ A hierarchy of SA components was identified through the identification of overarching themes and the components constituting these broad themes with progressively more specific foci.

\section{RESULTS}

\section{Included studies}

The search strategy identified 7285 articles. Title and abstract screening eliminated 6834 articles and full-text screening eliminated 425 articles, whereas 26 studies met the inclusion criteria (figure 1).

\section{Study characteristics}

Qualitative studies were primarily conducted in the USA $(n=13)$ and Canada ( $n=4)$ using purposive sampling 


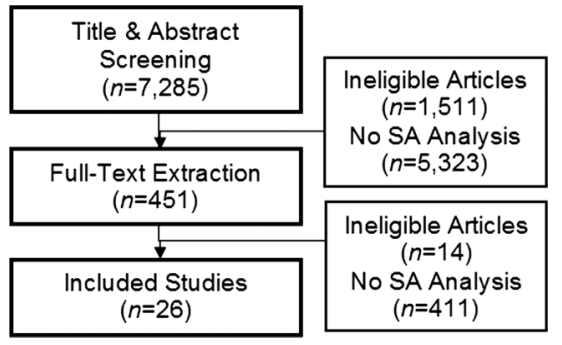

Figure 1 Inclusion flow chart.

with community dwelling populations of Caucasian older adults. The sample size ranged from 14 to 1771 , with a mean of $180($ median $=46 ; \mathrm{SD}=383$; table 1$)$.

\section{Components of SA}

All studies $(\mathrm{n}=26)$ included psychosocial components, $76 \%$ ( $\mathrm{n}=20$ studies) included biomedical components and $58 \%$ ( $\mathrm{n}=15$ studies) included external components. Psychosocial components were those that focused on internal and/or social phenomena, for example, resilience. Biomedical components were those that focused on physiological phenomena, for example, mobility. External components were those that focused on phenomena external to the individual, for example, housing conditions.

The biomedical components were grouped into cognitive and mental, health, health maintenance behaviours, longevity and physical health and functioning. Cognitive and mental components focused on the functioning of mental and cognitive faculties, for example, "the only way not to become an old dog is to learn new tricks." 14 Health components focused on non-specific notions of physiological health, for example, "health is everything". ${ }^{15}$ Health maintenance behaviour components focused on behaviours fostering physical and/or cognitive health, for example, "eating right" ${ }^{16}$ Longevity components were those that focused on length of life. Physical health and functioning components were those that focused on references to physical health, for example, "able to move anywhere"17 (figure 2).

External components were grouped into environmental factors, for example, "having a satisfactory living environment" and finances, for example, "[being] financially self-supported"18 (figure 3).

Psychosocial factors were grouped into acceptance, adjustment, maintenance, spirituality, community, social roles, quality of life, independence, prevention and remediation, self-awareness, perspective and engagement. Acceptance components focused on coming to terms with change in one's life, for example, "we need to accept our older age". ${ }^{19}$ Adjustment components focused on the ability to adapt to change in one's life, for example, "keeping up with the changing things around you". ${ }^{20}$ Maintenance components focused on continuing previous behaviours, for example, "there is one person I know who is quite old and they're still hunting and everything". 21 Spirituality components focused on the presence of a higher being or connection to a force greater than oneself, for example, "it is important to live with faith and appreciate that we are protected each day". ${ }^{22}$ Community components focused on connectedness or contributing to a social sphere, for example, "I'm active in the community. Very helpful to my neighbors in any way that I can". ${ }^{14}$ Social role components focused on one's position or function within a social sphere, for example, "being able to talk to young people, people younger than I who have a long life ahead of them". ${ }^{21}$ Quality-of-life components focused on life satisfaction, for example, "leading a simple but happy life". ${ }^{18}$ Independence components focused on autonomy, for example, "having the freedom to express myself freely and naturally". ${ }^{23}$ Prevention \& remediation components focused on the management or avoidance of negative influences, for example, abstaining from drugs and alcohol. ${ }^{24}$ Self-awareness components focused on personal resources, for example, "being able to look back on my life and see personal development". ${ }^{23}$ Perspective components focused on personal outlook and attitude, for example, "Having a positive outlook on life". ${ }^{25}$ Engagement components focused on social involvement, stimulation and/or participation in various activities, for example, "I like to be out around my friends talking, you know, what's going on in this place and finding out things, being involved"26 (figure 4).

A comparison of the percentage of respondents reporting each of the constituent components of SA revealed that engagement was mentioned most frequently, followed by perspective and self-awareness. Longevity was mentioned in two studies; in one of these studies mentioning longevity, 2 of 60 respondents mentioned longevity ${ }^{15}$ (figure 5). North American studies $(n=20)$ most often mentioned engagement $(95 \%$, $\mathrm{n}=19)$, perspective $(90 \%, \mathrm{n}=18)$ and self-awareness (80\%, $\mathrm{n}=16)$. Australian studies $(\mathrm{n}=2)$ mentioned engagement $(100 \%, \mathrm{n}=2)$, perspective $(100 \%, \mathrm{n}=2)$, independence $(100 \%, 2)$ and quality of life $(100 \%, n=2)$ most often. All Asian studies $(n=2)$ mentioned engagement, independence and quality of life, finances, environment and physical health. The South American study $(\mathrm{n}=1)$ mentioned engagement, perspective, self-awareness, independence, acceptance, finances, environment and health. The British study mentioned engagement, perspective, self-awareness, acceptance, quality of life, adjustment, finances, environment, cognitive and mental and health maintenance behaviours.

\section{DISCUSSION}

The components of SA identified by the qualitative studies captured in this review reflect a divergence from traditional biomedical conceptualisations of SA, highlighting the multidimensionality and psychosocial emphasis of SA. In contrast to the operational definitions captured in the most recent review of SA, which 
Table 1 Included study characteristics

\begin{tabular}{|c|c|c|c|c|c|c|c|c|c|c|c|c|}
\hline \multirow[b]{2}{*}{ Author } & \multirow[b]{2}{*}{$\mathbf{n}$} & \multirow[b]{2}{*}{ Population } & \multicolumn{5}{|l|}{ Age } & \multirow{2}{*}{$\begin{array}{l}\text { Ethnicity } \\
\text { Caucasian } \\
(\%)\end{array}$} & \multicolumn{4}{|c|}{ Marital status } \\
\hline & & & Mean & SD & Minimum & Maximum & Country & & $\begin{array}{l}\text { Married } \\
(\%)\end{array}$ & $\begin{array}{l}\text { Single } \\
(\%)\end{array}$ & $\begin{array}{l}\text { Divorced/ } \\
\text { separated (\%) }\end{array}$ & $\begin{array}{l}\text { Widowed } \\
(\%)\end{array}$ \\
\hline Bowling $^{34}$ & 854 & Community dwelling & 64 & & 50 & 94 & UK & & 72.0 & 5.0 & 9.0 & 14.0 \\
\hline Collings $^{21}$ & 38 & Inuit & & & 23 & 86 & Canada & & & & & \\
\hline Cupertino et $a^{35}$ & 501 & Community dwelling & 72.65 & 8.08 & 60 & 93 & Brasil & & & & & \\
\hline Duay and Bryan ${ }^{14}$ & 18 & Community dwelling & 72.6 & & 60 & 86 & USA & 94.4 & & & & \\
\hline Dionigi et $a \beta^{36}$ & 21 & Community dwelling women & 83.3 & & 75 & 92 & Canada & 100.0 & 14.3 & 4.8 & 0.0 & 81.0 \\
\hline Ferri et $a^{\beta 7}$ & 53 & Community dwelling & 78 & 8.2 & 61 & 90 & USA & 96.2 & 32.1 & 3.8 & 11.3 & 52.8 \\
\hline Fisher $^{25}$ & 40 & $\begin{array}{l}\text { Community dwelling, foster } \\
\text { grandparents }\end{array}$ & 72.65 & & 61 & 92 & USA & 97.5 & 2.5 & & 10.0 & 97.5 \\
\hline Fisher and Specht ${ }^{23}$ & 36 & Community dwelling artists & 73.75 & & 60 & 93 & USA & 97.2 & 66.7 & 5.6 & 5.6 & 22.2 \\
\hline Fisher $^{20}$ & 19 & Seniors' activity centre & 75 & & 62 & 85 & USA & 100.0 & 47.4 & 5.3 & & 47.4 \\
\hline Guse and Masesar ${ }^{38}$ & 32 & Long-term care & & & & & Canada & & 34.0 & 3.0 & 16.0 & 47.0 \\
\hline Hilton et $a l^{\beta 9}$ & 65 & $\begin{array}{l}\text { Caregivers of elderly } \\
\text { individuals }\end{array}$ & 51.8 & & 29 & 72 & USA & 81.5 & 59.4 & & & \\
\hline Hilton et $a{ }^{40}$ & 60 & Community dwelling Latinos & 61 & & 50 & 84 & USA & 0.0 & 48.3 & 16.7 & 20.0 & 16.7 \\
\hline $\mathrm{Hsu}^{17}$ & 584 & Community dwelling & & & & & Taiwan & & & & & \\
\hline $\begin{array}{l}\text { Iwamasa and } \\
\text { Iwasaki }^{22}\end{array}$ & 77 & $\begin{array}{l}\text { Community dwelling } \\
\text { Japanese-Americans }\end{array}$ & 78.3 & 8.5 & 55 & 96 & USA & & 37.7 & 3.9 & 11.7 & 46.8 \\
\hline $\begin{array}{l}\text { Knight and } \\
\text { Ricciardelli }^{15}\end{array}$ & 60 & $\begin{array}{l}\text { Community/retirement village } \\
\text { dwelling }\end{array}$ & 80.05 & & 70 & 101 & Australia & & & & & \\
\hline $\operatorname{Lee}^{18}$ & 109 & Living-alone, low SES & & & & & China & & 5.5 & 17.4 & 8.3 & 68.8 \\
\hline Lewis $^{19}$ & 15 & Alaska natives & 56 & & 26 & 84 & USA & & & & & \\
\hline Lewis $^{41}$ & 26 & Alaska natives & & & 61 & 93 & USA & & 53.8 & & & 46.2 \\
\hline McCann et $a \uparrow^{42}$ & 14 & Spiritually affiliated women & & & 60 & 89 & Australia & & & & & \\
\hline Reichstadt et $a f^{43}$ & 72 & Retirement communities & & & 60 & 99 & USA & & & & & \\
\hline Reichstadt et a ${ }^{26}$ & 22 & $\begin{array}{l}\text { Retirement communities/ } \\
\text { seniors' housing/seniors' } \\
\text { learning centre }\end{array}$ & 80 & 9.1 & 64 & 96 & USA & 86.0 & & & & \\
\hline Rossen et $a^{44}$ & 31 & Community dwelling women & 78 & & 61 & 90 & USA & & 20.0 & 12.0 & & 65.0 \\
\hline $\begin{array}{l}\text { Stevens-Ratchford } \\
\text { and Cebulak }{ }^{45}\end{array}$ & 14 & $\begin{array}{l}\text { Community dwelling with } \\
\text { osteoarthritis or rheumatoid } \\
\text { arthritis }\end{array}$ & 67 & & 61 & 87 & USA & 100.0 & & & & \\
\hline Tate et $a{ }^{46}$ & 1771 & $\begin{array}{l}\text { Community dwelling World } \\
\text { War II veterans }\end{array}$ & 78 & & & & Canada & & & & & \\
\hline Troutman et $a f^{47}$ & 100 & $\begin{array}{l}\text { Community dwelling } \\
\text { African-Americans }\end{array}$ & 74.4 & 6 & 61 & 89 & USA & 0.0 & & & & \\
\hline Troutman et $a l^{48}$ & 52 & $\begin{array}{l}\text { Community dwelling } \\
\text { self-identified "successful } \\
\text { agers" }\end{array}$ & 77.1 & 7.02 & 60 & 89 & USA & 44.0 & 25.0 & 15.4 & 3.8 & 53.8 \\
\hline
\end{tabular}




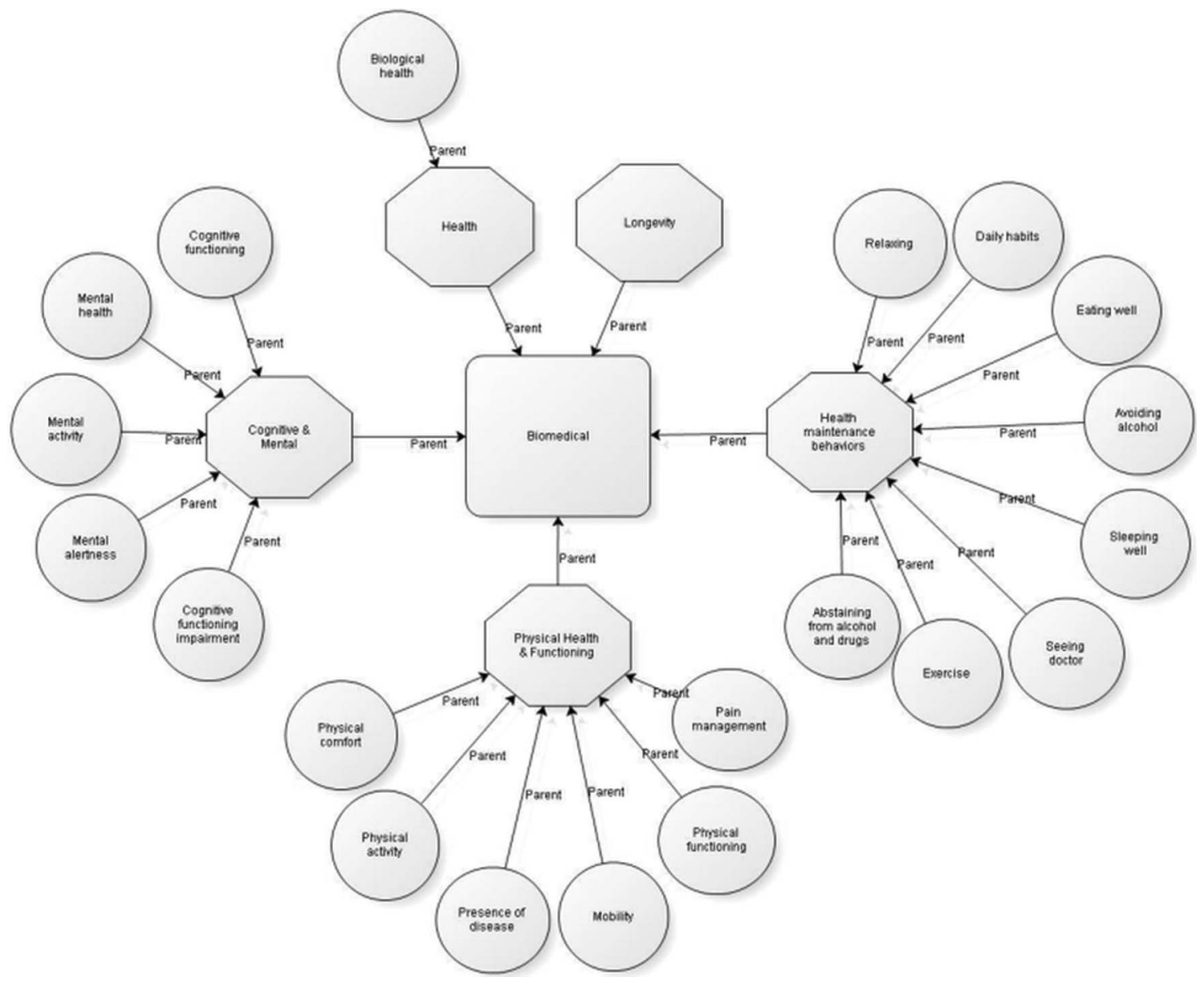

Figure 2 Biomedical themes and subthemes.

posit primarily biomedical models, ${ }^{1}$ attitudinal and engagement components were found to be the ones most frequently mentioned. Furthermore, external factors, such as finances and environment, which are absent in the majority of SA conceptualisations, ${ }^{1}$ were also frequently mentioned. This review highlights the importance of psychosocial and external factors in SA definitions and also emphasises the multidimensional nature of SA. These results suggest that the incorporation of psychosocial and extrinsic components identified by laypersons into a multidimensional model of SA is a prudent means with which to augment biomedical conceptualisations of SA.

Limitations in the current study include the subjective nature of meta-ethnography and issues with the translation of SA. Meta-ethnography involves the interpretation

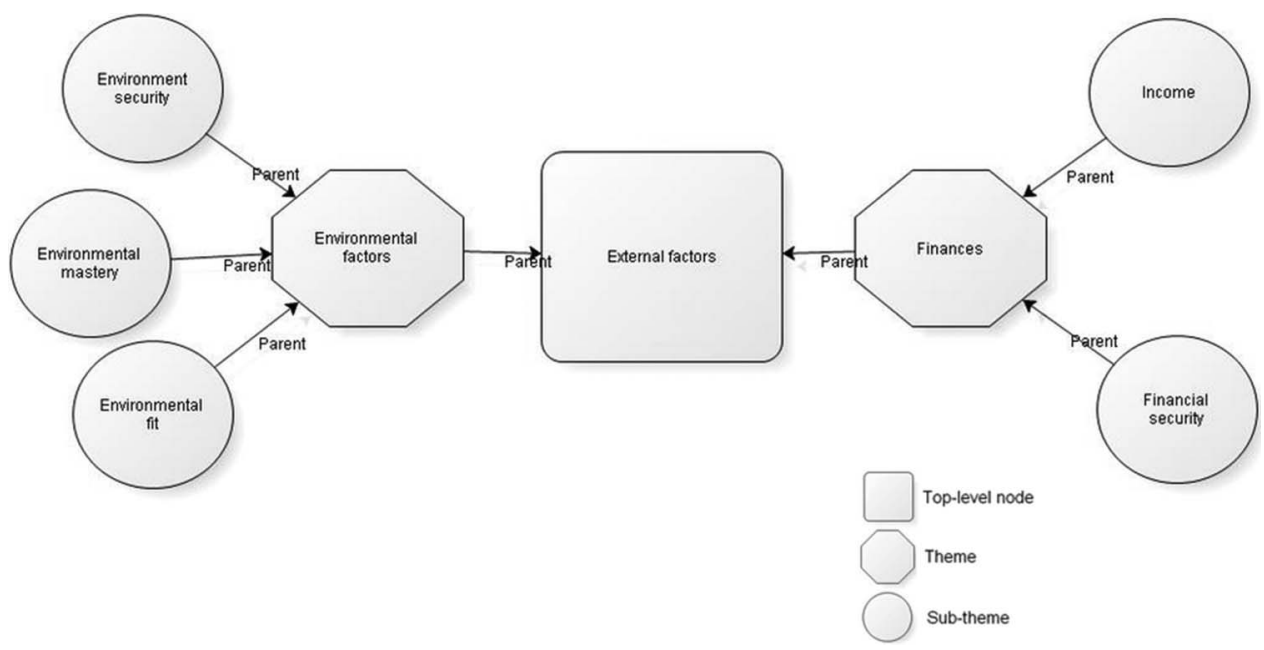

Figure 3 External factor themes and subthemes. 


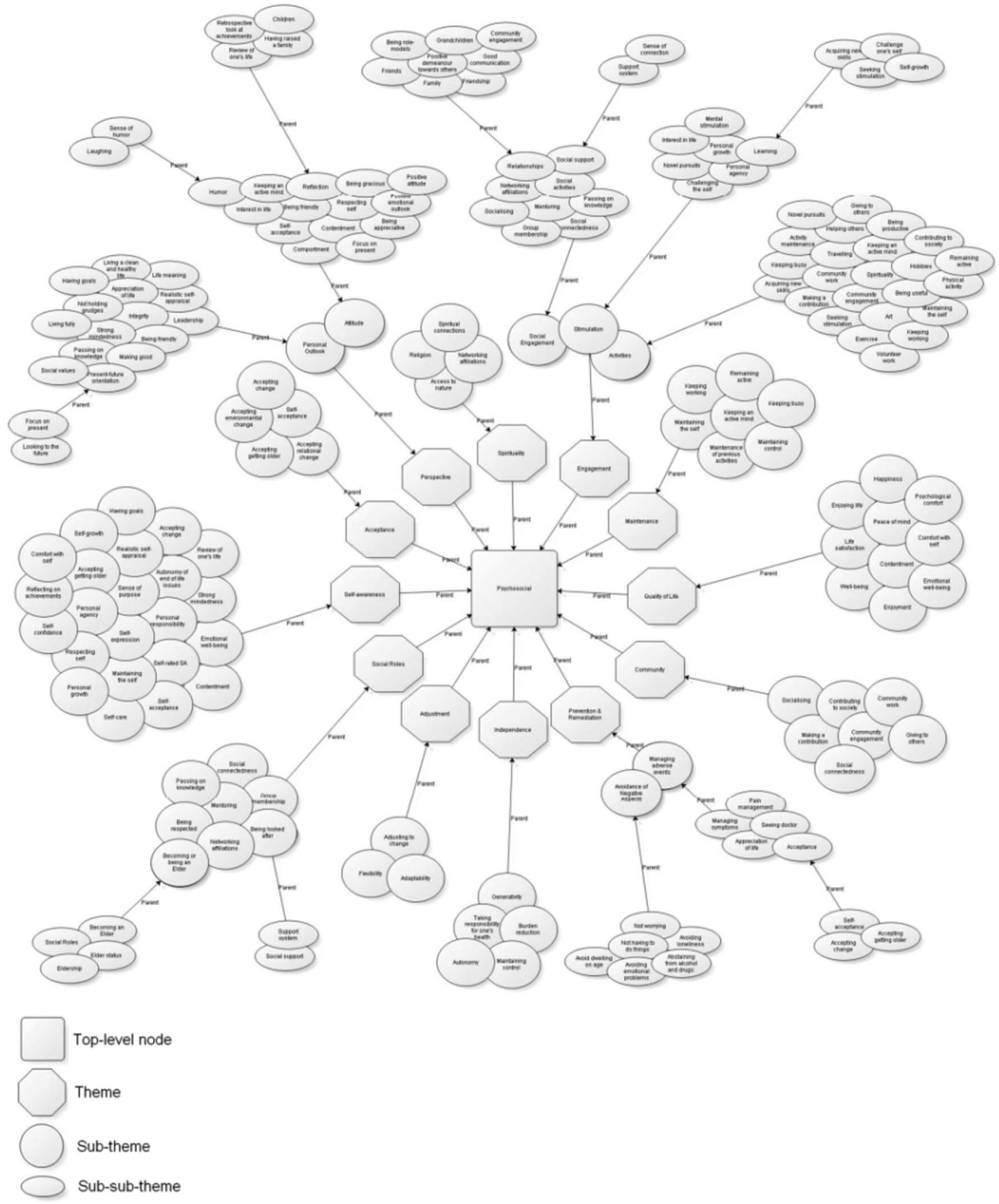

Figure 4 Psychosocial themes and subthemes.

and integration of researchers' interpretations of primary data ${ }^{13}$ that may result in bias. Where possible, direct quotes from respondents were coded; however, researchers' interpretive themes were coded primarily. A further limitation was the translation of the phrase 'successful ageing'. Non-English studies used phrases which the authors felt were equivalent to SA. For example, $\mathrm{Hsu}^{17}$ notes that there is no word that directly translates to SA in Taiwanese. The authors then used (what translates into English as) 'ideal or satisfactory life in old age', a phrase they identified as being roughly equivalent to SA in a pilot study.
Psychosocial components of SA were the most frequently mentioned aspects of SA, highlighting the advantages of expanding conceptualisations of SA beyond physiologically based models. Traditional models of SA often suggest that an individual's physiological health is the sole indicator of one's SA, which is, as the current study suggests, a parochial perspective of a multifaceted construct. Psychosocial components were suggested by laypersons in all the included studies, providing strong evidence for the inclusion in prospective models of SA. Furthermore, the breadth of the psychosocial components mentioned by laypersons highlights the multidimensionality of SA. 
Figure 5 Frequency of studies reporting each of the successful ageing components by region.

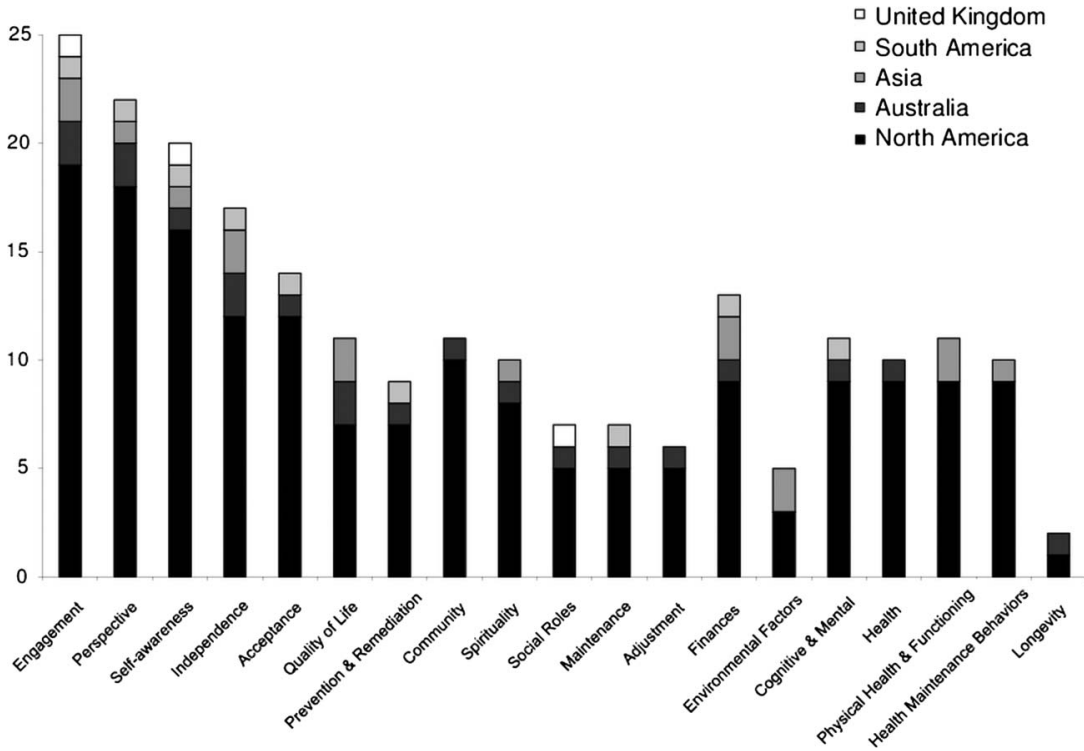

Using a meta-ethnographic framework, 12 psychosocial subthemes were identified: social roles, self-awareness, acceptance, perspective, engagement, spirituality, maintenance, quality of life, community, prevention and remediation, independence and adjustment. It is important to note the heterogeneity of these components even within this psychosocial umbrella, with components ranging from internal (eg, spirituality) to interpersonal (eg, social roles). This breadth of psychosocial components in SA has not been illuminated to this degree in previous studies, providing invaluable insight into the complexity of layperson perspectives of SA.

With such a variety of psychosocial components mentioned in the current review, including every aspect of layperson perspectives into models of SA becomes increasingly difficult. It would be unrealistic to expect a study to touch on every nuance of SA that has been captured in the current review; however, there are a number of emergent themes that would be possible to capture. Most significant is the prominence of psychosocial factors, notably engagement, perspective and selfawareness. These themes are then broken down into separate subthemes. This theoretical complexity manifests itself in attempts to quantify these psychosocial components of SA. There are a myriad of metrics that may be used to capture these phenomena, ranging from, for example, frequency of social interaction to selfconfidence, highlighting another area where further research is needed. Identifying appropriate metrics for capturing psychosocial SA phenomena presents a unique challenge for researchers: translating a nebulous concept into a quantifiable and practically relevant construct.

A component of SA identified in approximately two-thirds of the studies, but rarely examined in quantitative studies of SA, was extrinsic factors, that is, environment and finances. Financial security was found to be important across all age bands in Charbonneau-Lyons et $a l \mathrm{~s}$ study, ${ }^{27}$ in all permutations of gender, education and income, aside from females in the no/low education/income group in Nagalingam's study, ${ }^{28}$ and by all the respondents in the study by Lin. ${ }^{29}$ Environment and finances are typically excluded from current models ${ }^{3} 30$ and the identification of these factors in such a large number of studies is therefore a unique finding. Further research is needed to explore these factors crossculturally and along biomedical components of SA. The SA component that was least frequently identified as being important was longevity. This contrasts with biomedical approaches in SA research that typically focus on the extension of life. There have been previous suggestions that extreme longevity, in the form of centenarians, is a representative model of $\mathrm{SA} ;{ }^{31}{ }^{32}$ however, these models have met with opposition. ${ }^{33}$ Surviving to 100 is not necessarily indicative of holistic well-being and is often accompanied by great losses and/or physical deficits. ${ }^{33}$ The results from the current study support these assertions; elderly laypersons do not value simply living a long time as an integral component of SA. This departure from biomedical models supporting mere longevity aligns closely with the 'adding life to years, not just years to life' ethos.

Many of the components identified by laypersons as being important (eg, engagement, self-awareness, perspective, etc) present an opportunity for the implementation of specific interventions for modifiable behaviours. For example, aiding individuals in decreasing depressive symptomology, social engagement, and invoking coping and resilience training could augment and complement physical remediation strategies, as identified by biomedical models, in the pursuit of SA. Therefore, it is prudent to augment the scope of biomedical models to areas of the lived life that have not been covered by traditional models of SA.

There are important research and policy implications associated with the identification and acknowledgement of lay perspectives of SA. These data have the potential 
to provide invaluable information to researchers planning to conduct studies of SA through the incorporation of psychosocial variables into otherwise biomedical models. For example, if a researcher plans to use SA as an outcome variable, they have the opportunity to include psychosocial components in addition to physiological components. SA ageing is clearly not simply a physiological construct, so it seems intuitive that psychosocial components should be included in otherwise biomedical models of SA.

The distribution of the various SA components across regions reasserts the prevalence of psychosocial and external factors as components of SA. The only components that were represented in all five regions (North America, South America, Asia, Australia, the UK) were engagement and self-awareness. Given the profound over-representation of North American studies and studies conducted in Caucasian populations, it is hard to discern whether any cultural variations exist. These results highlight the need for further research to be conducted to augment and incorporate the influence of psychosocial components and cross-cultural perspectives of SA.

The current review reinforces the multidimensional nature of SA and emphasises the importance of the psychosocial aspects of SA. Components of engagement and personal resources were identified by laypersons in more studies than biomedical components, representing a divergence from traditional (biomedical) models of SA and highlighting the need for the inclusion of psychosocial components. Of particular note was the poor representation of longevity among lay perspectives of SA. Although the current study provides insights into the concept of SA, it must be acknowledged that the included studies represent a strong Anglophone bias. The current study updates and expands a previous review by Hung et al, ${ }^{7}$ collecting, synthesising and proving a comprehensive examination of layperson conceptualisations of SA.

Acknowledgements The authors would like to thank Yu-Tzu Wu for her assistance in the translation of non-English articles.

Contributors The review and search protocol was planned by TDC, BCMS and CB. TDC conducted the primary article review and data extraction; AMP and JP conducted the second, independent screens of the articles. TDC wrote the manuscript, which was edited and reviewed by AMP, JP, BCMS and CB.

Funding This research received no specific grant from any funding agency in the public, commercial or not-for-profit sectors.

Competing interests None.

Provenance and peer review Not commissioned; externally peer reviewed.

Data sharing statement No additional data are available.

\section{REFERENCES}

1. Depp CA, Jeste DV. Definitions and predictors of successful aging: a comprehensive review of larger quantitative studies. Am J Geriatr Psychiatry 2006;14:6-20.

2. Rowe JW, Kahn RL. Successful aging. Gerontologist 1997;37:433-40.

3. Rowe JW, Kahn RL. Human aging: usual and successful. Science 1987;237:143-9.
4. Folstein MF, Robins LN, Helzer JE. The Mini-Mental State Examination. Arch Gen Psychiatry 1983;40:812.

5. Katz S. Assessing self-maintenance: activities of daily living, mobility, and instrumental activities of daily living. J Am Geriatr Soc 1983;31:721-7.

6. Riley MW. Successful aging. Gerontologist 1998;38:151.

7. Hung L-W, Kempen G, De Vries N. Cross-cultural comparison between academic and lay views of healthy ageing: a literature review. Ageing Soc 2010;30:1373-91.

8. Bowling A, lliffe $S$. Which model of successful ageing should be used? Baseline findings from a British longitudinal survey of ageing. Age Ageing 2006;35:607-14.

9. Sofaer S. Qualitative methods: what are they and why use them? Health Serv Res 1999;34(5 Pt 2):1101-18.

10. Entwistle VA, Renfrew MJ, Yearley S, et al. Lay perspectives: advantages for health research. BMJ 1998;316:463-6.

11. Bowling $A$, Dieppe $P$. What is successful ageing and who should define it? BMJ 2005;331:1548-51.

12. Harden A, Garcia J, Oliver S, et al. Applying systematic review methods to studies of people's views: an example from public health research. $J$ Epidemiol Community Health 2004;58:794-800.

13. Noblit G, Hare RD. Meta-ethnography: synthesizing qualitative studies. Newbury Park, CA: SAGE Publications, 1988.

14. Duay DL, Bryan VC. Senior adults' perceptions of successful aging. Educ Gerontol 2006;32:423-45.

15. Knight T, Ricciardelli LA. Successful aging: perceptions of adults aged between 70 and 101 years. Int J Aging Hum Dev 2003;56:223-45.

16. Troutman M, Nies MA, Bentley M. Measuring successful aging in southern Black older adults. Educ Gerontol 2011;37:38-50.

17. Hsu HC. Exploring elderly people's perspectives on successful ageing in Taiwan. Ageing Soc 2007;27:87-102.

18. Lee J-J. A pilot study on the living-alone, socio-economically deprived older Chinese people's self-reported successful aging: a case of Hongkong. Appl Res Qual of Life 2009;4:347-63.

19. Lewis JP. Successful aging through the eyes of Alaska Natives: exploring generational differences among Alaska Natives. J Cross Cult Gerontol 2010;25:385-96.

20. Fisher BJ. Successful aging and life satisfaction: A pilot study for conceptual clarification. J of Aging St 1992;6:191-202.

21. Collings P. "If you got everything, it's good enough": perspectives on successful aging in a Canadian Inuit community. J Cross Cult Gerontol 2001:16:127-55.

22. Iwamasa GY, Iwasaki M. A new multidimensional model of successful aging: perceptions of Japanese American older adults. J Cross Cult Gerontol 2011;26:261-78.

23. Fisher BJ, Specht DK. Successful aging and creativity in later life. J Aging Stud 1999;13:457-72.

24. Lewis JP. Successful aging through the eyes of Alaska native elders. What it means to be an elder in Bristol Bay, AK. Gerontologist 2011:51:540-49.

25. Fisher BJ. Successful aging, life satisfaction, and generativity in later life. Int J Aging Hum Dev 1995;41:239-50.

26. Reichstadt J, Sengupta G, Depp CA, et al. Older adults' perspectives on successful aging: qualitative interviews. Am J Geriatr Psychiatry 2010;18:567-75.

27. Charbonneau-Lyons DL, Mosher-Ashley PM, Stanford-Pollock M Opinions of college students and independent-living adults regarding successful aging. Educ Gerontol 2002;28:823-33.

28. Nagalingam J. Understanding successful aging: a study of older Indian adults in Singapore. Care Manag J 2007;8:18-25.

29. Lin L-H. A study of successful aging of the elder learners in institutions in Taiwan. J Popul Stud 2006;33:133-70.

30. Baltes PB, Baltes MM. Successful aging: perspectives from the behavioral sciences. New York: Cambridge University Press, 1990.

31. Engberg H, Oksuzyan A, Jeune B, et al. Centenarians-a useful model for healthy aging? A 29-year follow-up of hospitalizations among 40000 Danes born in 1905. Aging Cell 2009;8:270-6.

32. Franceschi $\mathrm{C}$, Bonafe $\mathrm{M}$. Centenarians as a model for healthy aging Biochem Soc Trans 2003;31:457-61.

33. Motta M, Bennati E, Ferlito $L$, et al. Successful aging in centenarians: myths and reality. Arch Gerontol Geriatr 2005;40:241-51.

34. Bowling A. Lay perceptions of successful ageing: findings from a national survey of middle aged and older adults in Britain. Eur $J$ Ageing 2006;3:123-36.

35. Cupertino A, Rosa FHM, Ribeiro PCC. Successful aging definition in a sample of older adults. Psicologia-Reflexao E Critica 2007;20:81-6.

36. Dionigi RA, Horton S, Bellamy J. Meanings of aging among olde Canadian women of varying physical activity levels. Leisure Sci 2011;33:402-19. 
37. Ferri C, James I, Pruchno R. Successful aging: definitions and subjective assessment according to older adults. Clin Gerontol 2009;32:379-88.

38. Guse LW, Masesar MA. Quality of life and successful aging in long-term care: perceptions of residents. Issues Ment Health Nurs 1999;20:527-39.

39. Hilton JM, Kopera-Frye K, Krave A. Successful aging from the perspective of family caregivers. Fam J 2009;17:39-50.

40. Hilton JM, Gonzalez CA, Saleh M, et al. Perceptions of successful aging among older Latinos, in cross-cultural context. J Cross Cult Gerontol 2012;27:183-99.

41. Lewis JP. Successful aging through the eyes of Alaska native elders. What it means to be an elder in Bristol Bay, AK. Gerontologist 2011;51:540-9.

42. McCann Mortimer P, Ward L, Winefield H. Successful ageing by whose definition? Views of older, spiritually affiliated women. Australas J Ageing 2008;27:200-4.
43. Reichstadt J, Depp CA, Palinkas LA, et al. Building blocks of successful aging: a focus group study of older adults' perceived contributors to successful aging. Am J Geriatr Psychiatry 2007;15:194-201.

44. Rossen E, Knafl K, Flood M. Older women's perceptions of successful aging. Activities Adapt Aging 2008;32:73-88.

45. Stevens-Ratchford R, Cebulak BJ. Living well with arthritis: a study of engagement in social occupations and successful aging. Phys Occup Ther Geriatr 2004;22:31-52.

46. Tate RB, Lah L, Cuddy TE. Definition of successful aging by elderly Canadian males: the Manitoba Follow-up Study. Gerontologist 2003:43:735-44.

47. Troutman M, Nies MA, Mavellia H. Perceptions of successful aging in Black older adults. J Psychosoc Nurs Ment Health Serv 2011:49:28-34.

48. Troutman-Jordan M, Nies MA, Davis B. An examination of successful aging among Southern Black and White older adults. J Gerontol Nurs 2013;39:42-52. 